\title{
Climate negotiations from 1992 to 2011: changing issues and new stakes
}

\section{Venance Journé}

Centre International de Recherche sur l'Environnement

et le Développement (CIRED),

45 bis av. de la Belle Gabrielle, 94736 - Nogent sur Marne, France

Email: journe@centre-cired.fr

\begin{abstract}
This paper describes the main stages of the climate negotiations since the Earth Summit in Rio in 1992. After recalling the main components of the Kyoto Protocol, it describes the stakes in the discussions for developing countries as well as the increasing importance taken by these countries. It finally explains how the logic of binding commitments to reduce emissions, which was at the core of Kyoto negotiations, seems to be shifting to a logic of voluntary national reduction commitments.
\end{abstract}

Keywords: climate change; international negotiations; emerging countries; climate negotiation stakes; Kyoto Protocol.

Reference to this paper should be made as follows: Journé, V. (2012) 'Climate negotiations from 1992 to 2011: changing issues and new stakes', Atoms for Peace: An International Journal, Vol. 3, No. 3, pp.206-218.

Biographical notes: Venance Journé is a physicist and holds a Thèse d'Etat in Particle Physics. She is a researcher at the CIRED (International Research Centre on Environment and Development) linked with Centre national de recherche scientifique and the School of Advanced Social Studies, and formerly she was also programme officer of the Management and Impacts of Climate Change research programme of the French Ministry of Environment and Sustainable Development. Her current research interests focus on (1) climate change negotiations, interactions between climate change impacts and security and (2) the military nuclear programme, its history and its interaction with civilian programmes.

\section{Introduction}

During the early 1970s, awareness about depletion of natural resources, and then about the environmental consequences of the concomitant growths of population, economy and natural resource use, raised considerably the world over. Among these consequences, one of the most important is the climate change caused by an increased concentration of greenhouse gas (GHG), a phenomenon that was first described in 1896 by the Swedish scientist Arrhenius, and on which the scientists' warnings had reached policy makers in the mid-1980s.

At the Earth Summit in Rio de Janeiro in 1992, attended by 120 heads of state, three conventions were signed and they form the backbone of the multilateral treaties for sustainable development: the United Nations Framework Convention on Climate Change 
(UNFCCC), which now has 194 Parties, the Convention on Biological Diversity and the Convention on Desertification. Therefore, in Rio, the real issue was - sustainable development, and the participation of developing countries (DCs) was well recognised as essential to control the global consequences of these multiple growths.

Unlike many environmental problems in the past, such as the hole in the ozone layer, climate change is subject to considerable uncertainty whether the phenomena involved, their feedback, their magnitude, the consequences, especially regional, or the costs of damage and of the strategies to deal with them, such as emissions mitigation and adaptation to their impacts. Since any strategy should include measures on a global scale in sectors such as energy and land use, the stakes were high and governments needed the most objective information possible about the causes of climate change and its consequences, and the solutions that could be adopted. To meet this need, the Intergovernmental Panel on Climate Change (IPCC) was established in 1988 with a mandate to draw 'state of the art' knowledge on climate change. The IPCC, which includes several thousand scientists worldwide, establishes quadrennial reports following a strict procedure of double peer review.

In its Fourth Assessment Report, published in 2007, IPCC has warned in a more pessimistic fashion than before about the consequences of GHG emissions and thus on the need to drastically reduce them in the next few decades to avoid a climate catastrophe before the end of the XXIst century: the report states that global emissions have increased by $20 \%$ between 1995 and 2005, the emissions from industrialised countries (ICs) continue to grow and that the increase in temperature observed over the last 50 years is 'very likely' due to the increased GHG concentration. Already in 2001, the IPCC assessment report included a diagram showing that the effects of climate change will be particularly severe if global average temperature exceeds pre-industrial temperature by more than $2^{\circ} \mathrm{C}$ (GRID-Arendal, 2003). Although a danger threshold is difficult to quantify regionally, and even impossible globally, the value of $2{ }^{\circ} \mathrm{C}$ was considered as the limit not to be exceeded. This involves stabilising GHG concentrations at $450 \mathrm{ppm}$ and to this end, to divide global emissions by a factor 2 at the 2050 time horizon. Global emissions should start a decline from 2015 on, which is the so-called 'peak emissions'. ICs' present emissions should be divided by a factor 4 in 2050, and thus diminish by $25 \%$ to $40 \%$ in 2020 . As for DCs, they should follow emission trajectories substantially below that of their business-as-usual scenarios.

\section{1992-2001: a Protocol to limit emissions in industrialised countries, with assigned amounts to cap emissions and market tools to trade emissions rights}

Under Article 2 of the UNFCCC, the ultimate goal of the convention is to achieve the 'stabilisation of GHG concentrations in the atmosphere at a level that would prevent dangerous anthropogenic interference with the climate system'. On the grounds that ICs emissions contributed to their own development and that these are also the main cause of the climate problem, climate negotiations were structured around reducing emissions following the principle of 'common but differentiated responsibilities'. According to UNFCCC article 3.1, "The Parties should protect the climate system for the benefit of present and future generations of humankind, on the basis of equity and in accordance 
with their common but differentiated responsibilities and respective capabilities. Accordingly, the developed country Parties should take the lead in combating climate change and the adverse effects thereof": discussions were focused on the environmental component of climate change, which is GHG emission mitigation by ICs.

The Kyoto Protocol ${ }^{1}$ signed in 1997 defines 'assigned amounts' of GHG emissions that each Annex 1 Party (the ICs) should not exceed during the first commitment period, 2008-2012. The Protocol establishes three market mechanisms: the tradable emission permits allowing exchanges between Parties with reduction targets - which led to the establishment of an international carbon market among ICs - the Joint Implementation and the Clean Development Mechanism, both of which are projects mechanisms in order to obtain emission credits for reductions made in Eastern Europe or DCs. To lower the costs, these mechanisms provide a double flexibility: spatial (opportunities for trade between countries) and temporal (the reductions are recorded over a period of four years).

An international agreement on environmental policies may focus either on quantified reduction targets by country or on incentive instruments. In Rio, the OECD countries have pledged to stabilise emissions at 1990 levels and the negotiation was therefore engaged on an approach with reduction targets that are proportional to past emissions. The means of achieving these reductions were at the core of the discussions, economic efficiency - minimising costs - being the key parameter. Since each party is allowed to choose its favoured means, this has resulted in implementing a system of tradable emission permits: indeed, once the reduction targets are adopted, it is in each country's interest to be able to buy permits on the international market so as to avoid measures which would be too costly if implemented domestically (Baron et al., 1993).

The text to implement the Kyoto Protocol is a 250 pages document on which the Parties have agreed at the Conference of the Parties (COP) in Marrakesh in November 2001. It is the outcome of a difficult process which saw, among other things, the withdrawal of the USA, the largest emitter in the world at the time. Indeed, in March 2001, the USA announced that they would not ratify the Kyoto Protocol, since it would harm their economy and because all DCs were exempt from reduction commitments. This withdrawal has been the prelude to a long period of uncertainty and stagnation in the negotiations.

The Kyoto Protocol entered into force in 2005 after the ratification by Russia. It covers only $38 \mathrm{ICs}$, which accounts for a mere quarter of global emissions. The two major emitters, China and the USA, have no commitment, since USA did not ratify the Protocol that they had signed and China does not belong to the Annex 1 countries of the Kyoto Protocol, as well as other emerging countries, and therefore have no emission reduction target.

The objective of the Protocol was consistent with an emission reduction of 5.2\% worldwide compared to 1990. It is modest, disproportionate to what is necessary, but if compared with the current trends at the time, this represented a real break in sectors such as energy, transport and housing. This is the first - and still the only - legally binding commitment to reduce emissions and, as such, it represents a real breakthrough in terms of international law since countries have agreed to a loss of sovereignty for the protection of a common good. However, there is no supranational authority that can enforce the agreement and the penalties for non-compliance are imposed on the second commitment period, whereas, until now, only the first period was negotiated and it ends in 2012. 


\section{Developing countries and the rise of emerging countries}

The G77/China includes all DCs in a single negotiating block in the United Nations fora and it now has 130 members. It is a very heterogeneous group, in terms of wealth, emissions or vulnerability to climate change. Several sub-groups of countries have very divergent interests and defend positions which are diametrically opposed on various aspects of the negotiations. On the one hand, the vast majority of OPEC countries, especially Saudi Arabia, but with the notable exception of Iran, are doing everything possible to slow or even block the negotiations. On the other side of the spectrum, some countries particularly vulnerable to the impacts of climate change, which are already experiencing its effects, are therefore in favour of strengthening reduction commitments: the least developed countries whose economy is predominantly agricultural, and therefore very sensitive to perturbations in precipitation, and the Alliance of Small Island States (43 states) for which the rising sea level - and the increased frequency of hurricanes - may make their territory uninhabitable at the time horizon of a few decades. It is noteworthy that the negotiating position of the G77/China is remarkably united and stable since the beginning, one of the reasons being the common interest of these states in maintaining national sovereignty and respect for the right to economic development (Kasa et al., 2008).

The negotiation of the Kyoto Protocol, mainly led by the ICs, has focused on reducing IC emissions and the crucial question of DC development trajectories has been ignored. However, it was essential that DCs engage from the beginning in low carbon development patterns for the two following reasons:

1 GHG concentrations have since long reached an alarming level, DC participation is therefore necessary

2 relevant time constants are measured in decades for the implementation of technologies in the energy, transport and housing sectors as well as for the infrastructure lifetime.

However, DCs have always been strongly united in their opposition to any request upon them for reduction commitments for three reasons. First, they consider climate change as a long-term issue, their most urgent priorities concern poverty reduction and development. DCs have always asked for financial transfers and technologies in this respect.

Second, the equity issue in the resource sharing modalities, in the case of the atmosphere, was never really addressed: this is the main source of problems in the negotiations since 2001. Indeed, emission mitigation involves a discussion of the rights to use the atmosphere and the Kyoto Protocol logic - reduction in proportion to past emissions - disadvantages the DCs. Their concern is not so much to know the date at which they will enter the system to limit emissions, but it is the rule according to which emission rights will be allocated. DCs, and especially the biggest among them, were well aware of their weak position in the negotiations and of the inevitable increase in their emissions, and they feared that it could result later in an agreement which transfers to them much of the reduction load (Shukla, 1999).

Third, the asymmetry of climate change where people least responsible for the problem are exactly those that are most negatively affected because of their specific geographical circumstances and by lack of financial and technological resources. These 
most vulnerable populations will have to adapt, but the magnitude of impacts and adaptation costs are still highly uncertain. Taking into account the damages is an essential aspect of equity and DCs are requiring funds from ICs by way of compensation.

In recent years, the economic and demographic weights of major emerging countries, such as Brazil, China and India, give them a leading position in the G77/China. These countries have experienced remarkable economic growth, accompanied by a sharp increase in emissions, which makes their participation an essential component of any global emission reduction strategy. Indeed, China's emissions have increased from $6 \%$ of global emissions in 1973 to $22 \%$ in 2008 and have now surpassed those of the USA. However, DCs' per capita emissions are much lower than those of ICs and will remain so until at least the end of the century: in 2008, per capita emissions from fossil fuels were $4.91 \mathrm{t} \mathrm{CO}_{2} /$ cap in China, $1.25 \mathrm{t} \mathrm{CO}_{2} /$ cap in India, and $1.90 \mathrm{t} \mathrm{CO}_{2} /$ cap in Brazil, the average for non-OECD countries was $2.86 \mathrm{tCO}_{2}$ /cap, while the OECD average is $10.61 \mathrm{t} \mathrm{CO}_{2} /$ cap and that of the USA is $18.38 \mathrm{t} \mathrm{CO}_{2} /$ cap (IEA, 2010).

These emerging countries feel strong enough to negotiate directly with ICs and they enter into partnerships and bilateral agreements in energy technology with the USA or the European Union (EU), linking development assistance, energy technologies and climate change. For example, the 'Asia-Pacific Partnership on Clean Development and Climate' brings together eight countries representing half the global population and half the energy consumption, and it aims at developing clean energy technologies; the USA and India have a partnership to improve access to energy and promote a low carbon growth by green technology research and dissemination. These partnerships have been negotiated without compensation in emission reductions, so emerging powers have therefore even less incentive to consider binding commitments, and this contributes to the continued intransigence of the G77/China on this issue.

Nevertheless, climate change is a real concern of the leaders of these countries since they are already experiencing the effects of increasing pressure on water resources (drought, flooding, loss of glaciers in the Himalayas, etc.). In the China's National Climate Change Program, published in June 2007, the Chinese government pledged to restructure the economy, promote clean energy technologies and improve energy efficiency. Following the publication of the IPCC alarmist projections in 2007, the major countries announced significant reduction measures. China has included a 'cap and trade' system in the fifth plan (2011-2015). In 2009, in Copenhagen, China and India announced targets to reduce emissions per unit of GDP: $40-45 \%$ in 2020 compared to 2005 for China and 24\% for India. However, these figures represent net GHG increases for economic growth of the same order of magnitude as that of previous years.

China invests heavily in renewable energy: $\$ 54.4$ billion in wind, solar and other green technology energy projects, an increase of $39 \%$ over the previous year, ahead of Germany, $\$ 41$ billion, and the USA, $\$ 34$ billion. Chinese companies have produced nearly half of the solar modules and wind turbines in the world (The Pew Charitable Trusts, 2010).

Finally, in order to coordinate their negotiating positions, Brazil, China, India and South Africa have formed a group, called BASIC, at a meeting in Beijing in November 2009. As discussed later, this group has become a major force in the COP negotiations in Copenhagen. 


\section{Two negotiating tracks for the 'post-2012'}

A new phase of negotiations started in 2002 and discussions focused on the future, the 'post-2012', on the type of agreement to set up after the first commitment period of the Protocol. The other subject, which started to be addressed in a limited fashion, relates to adaptation to climate change. The IPCC Third Assessment Report, published in 2001, highlighted the fact that emissions continue to rise and that negative impacts were beginning to be felt: it identified areas of pressures on resources (water) and fragile ecosystems, as well as economic activities (agriculture) that would be affected. The negotiations therefore addressed the adaptation policies, which would require the provision of new funds for poorest countries.

The discussion agenda concerned the four areas of action for the future climate regime: GHG emission mitigation, adaptation to climate change, development and technology transfer, and financing. Two working groups were created. Working in parallel, they were to achieve proposals to be adopted at the Copenhagen COP in 2009. They are:

1 the 'Working Group on Further Commitments for Annex I Parties under the Kyoto Protocol' (AWG-KP) with a mandate, on the basis of Article 3.9 of Protocol, ${ }^{2}$ to propose an amendment to the Protocol on IC commitments for periods after 2012. This group was established at the Montreal COP in 2005

2 the 'Ad Hoc Working Group on Long-term Cooperative Action under the Convention' (AWG-LCA) established at the COP in Bali in 2007, aims at negotiating the actions to be implemented by all parties to support the objective of the Climate Convention. It is a holistic approach - the 'long-term shared vision' with IC mitigation commitments and 'nationally appropriate mitigation actions' (NAMAs) by DCs, as well as adaptation actions, technology transfer, and financial flows and investments. Reducing emissions from deforestation or forest degradation was also included in the group's mandate. Nothing was said about the legal form of the future agreement: COP decision, amendment to the Convention or new international treaty.

The question quickly arose as to whether these groups should reach a single agreement or separate agreements such as an amendment to the Kyoto Protocol and another to the UNFCCC. Many ICs (Australia, Canada, Japan, Russia, for example) would not accept new commitments in the absence of binding commitments from the USA and from some major DCs, particularly emerging countries: therefore they prefer a single overall agreement, in merging the two negotiating tracks (AWG-LCA and AWG-KP), which would replace the Kyoto Protocol. The USA indicated since 2001 that any possible commitments or actions would be decided unilaterally and is obviously in favour of a single agreement. The EU is committed to unilaterally reduce its emissions in 2020 by 20\% compared to 1990 as stated in the Climate Action Plan released in February 2007. The EU indicated in 2009, that this value could reach $30 \%$ if this reduction is part of a global agreement and if the USA, among others, participates in it.

On the contrary, DCs are strongly opposed to a single agreement and they insist that the Kyoto process should continue (Lin, 2009). These two negotiating tracks were considered necessary and complementary to maintain further binding commitments on the part of States Parties to the Kyoto Protocol and also for the USA to take, under the Convention, commitments comparable to those of other ICs. DCs committed to take action to reduce their emissions through the implementation of NAMAs, provided they receive financial support and technology transfer. 
However, the two working groups had made little progress, especially during 2009, despite numerous preparatory meetings. It was therefore unlikely that anything else than a political declaration without binding commitment could be reached in Copenhagen, the two working groups having not been able to conclude their negotiations by the deadline that had been specified in Bali.

\section{Copenhagen Conference of the Parties (COP15, December 2009)}

On 22 September 2009, a hundred Heads of State gathered in New York for the UN Summit on Climate Change and they expressed their political will to achieve a significant result in Copenhagen. The 2009 COP had raised high expectations because it was supposed to be a turning point in the future reduction commitments and to reach an agreement for the 'post-2012'. This resulted in an unprecedented media coverage on the stakes and implications of the fight against climate change. The number of participants was the highest of any COP: hundreds of ministers, including 115 Heads of State or Government, and over 45,000 registrants, participants in the national delegations, NGOs, private sector and observers.

The usual dichotomy between DCs and ICs was, as always, the main fault line in the discussions, despite very divergent interests within the G77/China. For the first time the DC emissions were discussed but DCs do not want to hear about a reduction in their emissions before ICs have achieved ambitious reductions in accordance with what scientific findings require - as a matter of fact, for example, US emissions are $17 \%$ higher in 2007 than in 1990 (US Department of Energy, 2008). DCs refused that the funding they request since the beginning be linked to reduction commitments. The other bone of contention, having provoked heated discussions between China and the USA, concerned international verification of NAMAs. The USA insisted on the need for guarantees from emerging countries on their policies to reduce emissions as well as transparency in reduction accounting. As for China, it believes that emission accounting should be based on consumption rather than production as is the case now, since about a quarter of Chinese emissions are due to the production of goods sold abroad. There were also heated discussions on the prerogatives of the organisation which would have the authority to verify, and on national sovereignty issues.

After a very chaotic process, the COP ended with an informal accord limited to three pages. In the end of the conference, the final text was negotiated in extremis the last night between President Obama and the leaders of the BASIC four emerging countries. When Obama announced on television that he had obtained an agreement, most other delegations had not even read it (BBC, 2009). Although the accord was deemed unsatisfactory by the majority of countries, almost all have accepted it in order to avoid a collapse of the UN process. Strong opposition from several Latin American countries has prevented the agreement from becoming a formal UN document and it has therefore only been 'taken note' of.

The accord, summarised in Appendix A, contains several new elements: (1) a threshold of danger $-2^{\circ} \mathrm{C}$ global temperature rise - not to be exceeded (2) a process of international verification of emission reductions and (3) significant financial contributions. ICs commit to implement quantified emissions targets for 2020, to communicate them before end of January 2010. Finally, emerging countries, which must be part of the solution to the emissions ceiling, agreed that their emissions be discussed and subject to international scrutiny. 
This agreement was received in very different ways. DCs and many analysts felt that this result is a clear step back from the Kyoto process: it contains no long-term global goal or timetable for the emissions to start to decline, it is not legally binding, it is silent on the second commitment period although it seems increasingly sure that some ICs will not be able to meet the Kyoto commitments. For example, instead of reducing GHG emissions by $6 \%$, Canada has exceeded its Kyoto's commitments by $34 \%$. Although Japan had pledged to decrease its emissions by $6 \%$, in 2007 , these had already increased by $9 \%$ compared to their 1990 level. The accord does not indicate the sources of funding or how funds will be allocated, and it does not guarantee that they will materialise. Finally, the accord appears to initiate a transition from the 'top-down' logic of the Kyoto Protocol to a 'bottom-up' one, advocated by the USA, which specifies only voluntary national objectives, to be submitted to the Convention only for information purpose. For the same reason, some US analysts welcomed the agreement (Bodansky, 2010).

Finally, the bargaining process adopted by the COP Danish Presidency has been strongly criticised for being 'non-transparent' and 'undemocratic': many meetings were held in very small committees and the original text of the agreement had been discussed in the last two days of the conference, among a limited (25) set of parties representing $80 \%$ of global emissions.

As of 25 June 2010, 136 parties are associated with the Copenhagen accord, including 40 ICs having stated their reduction targets and 30 DCs, most of which have established, apart from a quantified national target, a description of proposed actions by sector, project or city. These actions are conditional on the granting of sufficient funding and technological assistance by the ICs.

\section{Cancun Conference of the Parties (COP16, December 2010)}

After the disappointment of Copenhagen and the over-mediatisation of controversies about the IPCC report contents from the part of virulent 'climate skeptics' currents internationally, there was a high risk of demobilisation among politicians and the population. All parties were very aware that a failure in the Cancun COP would probably give a fatal blow to the UN multilateral process.

Moreover, the year 2010 had been particularly rich in cataclysmic events such as those projected by climate models - uncontrollable fires in Russia, floods of the century in Australia, or torrential rains in South Asia (Pakistan, Laddakh) with catastrophic consequences (millions of homeless in Pakistan). It had also been the hottest of all years recorded since 1990 (World Meteorological Organisation, 2010). Finally, in November 2010, the United Nations Environment Program published a report written by scientists and entitled 'The Emissions Gap'. The report estimated (1) that 2020 global emissions would reach 49 gigatons $(\mathrm{Gt})$ of $\mathrm{CO}_{2}$ if the reduction promises made by the Parties in Copenhagen are met in the best conditions, which is far from assured, and (2) that emissions corresponding to a $450 \mathrm{ppm}$ concentration threshold should not exceed $44 \mathrm{Gt}$ of $\mathrm{CO}_{2}$. To give an idea of the magnitude, this difference of $5 \mathrm{Gt}$ is equivalent to 2005 global land transportation emissions (United Nations Environment Program, 2010).

Between the Copenhagen and Cancun COPs, the two working groups met four times in Bonn (Germany) and Tianjin (China). Most DCs insisted that the ICs commit for the second Kyoto Protocol period, while the majority of ICs preferred a single agreement which encompasses all major emitters under the AWG-LCA. According to the words of one senior delegate in Tianjin, the COP must adopt a decision that "keeps the Protocol alive enough for DCs, but dead enough for ICs - basically keep it on life support" (Earth Negotiation Bulletin, 2010). 
The Cancun agreement, a 33-page text, endorses the Copenhagen decisions and makes them operational by the implementation of several technical mechanisms on adaptation, technology and financing (see summary in Appendix B). The agreement does not mention the agricultural sector which nevertheless contributes to $14 \%$ of GHG emissions. The Parties failed to agree on two aspects, the extension of the Kyoto Protocol and the equitable sharing of reduction targets, and they left the task of solving them to the next COP - in Durban (South Africa) in December 2011. There is no deadline for work completion for the AWG-KP responsible for these issues. However, the text specifies that they must be completed 'in time, to ensure that there is no gap between the first and second commitment periods' and the conclusions of the AWG-LCA stress the need for IC significant reductions according to the principle of 'common but differentiated responsibilities'.

The agreement's major positive aspect is the set of decisions on the institutional infrastructure needed to promote sustainable low-carbon development, in which the representation of the DCs will be equal to that of the ICs. The ICs historical responsibility is listed in the text and the GHG emissions reduction promises, made in 2010 following the Copenhagen Accord, are now part of an official text. Nevertheless these will still lead to a $3-5^{\circ} \mathrm{C}$ net increase in global temperature by the end of the century. All countries, including and especially the large emitters, must develop national mitigation plans to be submitted to an international review. The fact that information can be available is important.

This agreement raises serious concern among DCs. In the wake of the Copenhagen accord, it seems to be a new step in the transition from a regime with binding commitments for ICs to an 'à la carte' system providing for voluntary commitments, such as the USA 'pledge and review' model, going in the direction of a gradual disappearance of the clear distinction between the ICs and DCs. In the USA, this trend is seen as 'another step in the right direction' (Stavins, 2010). The agreement contains new requirements for DCs, which will require financial and personnel resources as well as know-how they do not have (Khor, 2010). Finally, the origin of funds is not specified.

While this text has not fully satisfied any party, it has almost universally been regarded as 'balanced'. It was accepted by all except Bolivia (Solon, 2010). After the debacle in Copenhagen, an agreement in Cancun was essential to put back the UN process on track and 'save multi-lateralism' as stated by the Mexican Foreign Minister, President of the COP, Patricia Espinoza, in the final declaration. This was clear to all parties, especially to those for which the only accessible negotiating forum is the UN. ${ }^{3}$ The agreement was also facilitated by a remarkable improvement in the tone of exchanges between China and the USA, neither of two countries wishing to be held responsible for a failure of the COP. Finally, the agreement was also obtained through the determination and effectiveness of the Mexican presidency that has led the negotiations in a 'transparent and inclusive' fashion. The most important advances in this agreement are the technical mechanisms implemented that should allow real progress on the field.

The issue of extending the Kyoto Protocol will be a thorny issue. As they have stated again in Bangkok in April 2011, Japan and Russia, particularly adamant on this issue, refuse to subscribe to a second commitment period. On the other side, emerging countries remain very firm on the fact that the two tracks of negotiations agreed at Bali must continue, one under the Kyoto Protocol, with binding reduction commitments, and the other under the Convention. The leaders of the BASIC group, and Argentina (chairing the G77/China), Algeria (chairing the African Group) and the Maldives (chairing the Alliance of Small Island States) met in New Delhi in February 2011. They stated that a second commitment period under the Kyoto Protocol is critical to achieving the overall 
goal of reducing emissions and that decisions in this regard should be taken no later than the Durban COP to avoid an interval between the two commitment periods. They stressed the need to maintain a balance between the obligations of ICs vis-à-vis those of DCs. They consider that funding and this issue will be the two key points for success in future negotiations. The Quick Start Fund for Africa, Small Island States and least developed countries, promised in Copenhagen, has as yet only reached negligible sums, and countries like the USA or the EU are trying to include into these funds, some funding which was intended to other more affluent countries (India and Brazil) (Singh, 2011). According to the words of Shri Ramesh, Indian Minister of Environment and Forests: "Unless countries begin to see money flowing, the atmosphere at Durban would continue to be clouded by doubts and suspicion" (INVC, 2011). Finally, Ministers agreed that equity, trade and intellectual property rights issues not being listed in the Cancun agreement, it was necessary that they would be examined in the upcoming discussions (BASIC, 2011).

\section{Conclusions}

The negotiation leading to the Kyoto Protocol has been focused on emissions without considering the DCs development needs - including poverty alleviation and food security - and the economic takeoff of the large emerging countries. The difficulties in the current negotiations on the extension of the Kyoto Protocol and the equitable sharing of commitments show the limitations of this approach. Considering DCs' development needs as well as making sure that their development follows a low carbon emission path are two necessary conditions to solve the climate problem: to this end, a massive shift in investment towards low-emission technologies will be indispensable, requiring incentive policies, which are appropriate and innovative. Institutional technological and financial support mechanisms, agreed upon in Cancun, if they are implemented and if the funds are raised, will allow progress in this direction.

The initial agreement was based on the 'top-down' logic of a legally binding agreement with reduction targets. The bottom-up negotiation logic supported by the USA, is now also included in the Cancun Agreement since the agreement establishes a process providing for national voluntary commitments that are decided unilaterally. The absence of penalty for non compliance by a party is a serious deficiency of the Kyoto Protocol and it will not be possible to remedy it if only this new 'bottom-up' logic is taken into account in the future agreement.

In the past, ICs, were leading the negotiations since they were concentrating economic power, access to natural resources and technology, and mastery of scientific knowledge. The rise of emerging countries is rapidly changing these asymmetrical conditions. DCs are firm in their requests for consideration of equity issues and concrete and ambitious actions by the ICs. It is only if the negotiations really address these issues that there will be a chance to limit the major climate disruptions ahead.

\section{References}

BASIC (2011) Joint Statement Issued at the Conclusion of the Sixth Basic Ministerial Meeting on Climate Change, New Delhi, India, 26-27 February 2011.

Baron, R., Hourcade, J.C. and Godard, O. (1993) Les instruments économiques internationaux et le changement climatique, OECD, Paris.

BBC (2009) 'Climate talks battle to save deal', $B B C, 19$ December. 
Bodansky, D. (2010) 'The Copenhagen Climate Change Conference: a post-mortem', The American Journal of International Law, Vol. 104, No. 2, April 2010.

Earth Negotiations Bulletin (2010) 'Summary of the Tianjin climate change talks', Earth Negotiations Bulletin, 4-9 October 2010.

GRID-Arendal (2003) Climate Change 2001: Working Group II: Impacts, Adaptation and Vulnerability. Available online at: http://www.grida.no/publications/other/ipcc_tar/?src=/ climate/ipcc_tar/wg2/index.htm

IEA (2010) $\mathrm{CO}_{2}$ Emissions from Fuel Combustion, IEA Statistics, 2010. Available online at: http://www.iea.org/co2highlights/co2highlights.pdf

INVC (2011) 'There are three very important issues for BASIC quartet: Jairam Ramesh', International News and Views Corporation. Available online at: http://www. internationalnewsandviews.com/2011/02/28/there-are-three-very-important-issues-for-basicquartet-jairam-ramesh/

Kasa, S., Gullberg, A.T. and Heggelund, G. (2008) 'The Group of 77 in the international climate negotiations: recent developments and future directions', International Environment Agreements, No. 8, pp.113-127.

Khor, M. (2010) 'Complex implications of the Cancun Climate Conference', Economic and Political Weekly, Vol. 14, No. 52, 25 December 2010.

Lin, L.L. (2009) 'Why we need to save the Kyoto Protocol', Third World Network, Briefing Paper No. 57, November 2009.

Shukla, P.R. (1999) 'Equity and efficiency in climate change, a developing country perspective', in Toth, F. (Ed.): Fairness Concerns in Climate Change, Earthscan Publications, London.

Singh, S. (2011) BASIC Needs a New Strategy, 4 March 2011, The Institute of Peace and Conflict Studies. Available online at: http://www.ipcs.org/article/india/basic-needs-a-new-strategy3337.html

Solon, P. (2010) 'Why Bolivia stood alone in opposing the Cancún climate agreement', The Guardian, 21 December 2010. Available online at: http://www.guardian.co.uk/environment/ cif-green/2010/dec/21/bolivia-oppose-cancun-climate-agreement

Stavins, R. (2010) 'What Happened (and Why): An Assessment of the Cancun Agreements', Harvard Project on Climate Agreements, 13 December 2010.

The Pew Charitable Trusts (2010) Who's winning the clean energy race, G-20 Clean Energy Factbook, The Pew Charitable Trusts, PA, USA.

United Nations Environment Program (2010) The Emissions Gap Report, Are the Copenhagen Accord Pledges Sufficient to Limit Global Warming to $2^{\circ} \mathrm{C}$ or $1.5^{\circ} \mathrm{C}$ ?, A preliminary assessment, November 2010

US Department of Energy (2008) Emissions of greenhouse gases in the United States in 2007, Energy Information Administration, Office of Integrated Analysis and Forecasting, US Department of Energy, December 2008.

World Meteorological Organisation (2010) WMO statement on the status of the global climate in 2010.

\section{Notes}

1 The UNFCCC is a framework convention: it has been amended with several agreements, such as the Kyoto Protocol or the Cancun agreement.

2 The Conference of the Parties serving as the meeting of the Parties to this Protocol shall initiate the consideration of such commitments at least seven years before the end of the first commitment period referred to in paragraph 1 above.

3 Climate change is regularly on the agenda of the G8 and G20 meetings. 


\section{Appendix A: Copenhagen Accord}

1 Shared Vision: Parties recognise the need to limit global temperature increase to a maximum value of $2^{\circ} \mathrm{C}$, they 'agree that deep cuts in global emissions are required according to science' and therefore that they 'should cooperate in achieving the peaking of global and national emissions as soon as possible'.

2 Priority for Adaptation: urgent need to strengthen actions undertaken for adaptation and vulnerability reduction for the most vulnerable DCs (least developed countries, Island States, Africa), and that ICs 'shall provide adequate, predictable and sustainable financial resources, technology and capacity-building'.

3 Voluntary commitments from ICs to reduce their emissions by 2020 and from DCs to develop national mitigation actions. The objectives are to be submitted to the Secretariat of the Convention before 31 January 2010.

4 Establishing a system to measure, report and verify for ICs emission reduction commitments and for DCs national actions which shall present the results every two years in their national communications.

5 Granting of 'scaled up, new and additional, predictable and adequate funding' from the ICs: a quick-start funding of $\$ 30$ billion over the 2010-2012 period, and a IC collective target to 'mobilise' $\$ 100$ billion per year by 2020 for DCs, from public or private sources (sources which are not specified). A 'Copenhagen Green Climate Fund' is created as 'an operating entity of the financial mechanism of the Convention'.

6 Establishment of a Technology Mechanism to accelerate technology development and transfer in support of action on adaptation and mitigation. 


\section{Appendix B: Cancun Agreement}

- Establishment of a Technology Mechanism that includes a Technology Executive Committee, with 20 experts, 9 from ICs, 11 from Dcs, and a Climate Technology Centre and Network to promote the transfer and sharing of green technologies. The mandate of the Executive Committee also includes assessing needs and making recommendations.

- Establishment of the Cancun Adaptation Framework to coordinate adaptation actions in DCs and help them assess their vulnerabilities.

- Sealing in the Convention of the reduction commitments by 80 countries as a result of the Copenhagen Accord. The text also notes the overall quantified emission reduction target to be implemented by Annex 1 parties and urges them to define ambitious targets so as to reduce global emissions to a level compatible with the IPCC Fourth Assessment Report recommendations. The agreement also includes a decision to strengthen ICs reporting procedure for national communications on emission reductions and on technological and financial support for capacity building for DCs.

- Agreement on the system of 'measure, report and verification': only countries that have received international funding will be subject to international verification of emission reductions, the other making biennial reports on national progress. The information will be evaluated in a process of 'international consultation and analysis' by a forum of experts and representatives of the concerned parties.

- Agreement to reduce deforestation, including guidelines for the implementation of actions to reduce GHG emissions from deforestation and land use changes; financial aspects, with the difficult issue of including this process in a carbon market, are left for the next COP.

- Incorporation of the Copenhagen decisions on funding: establishment of a Green Climate Fund, with a Council and equitable representation among DCs and ICs, under the aegis of the COP, administered by the World Bank for a probationary period of three years; the ICs grant a $\$ 30$ billion Quick Start Fund between 2010 and 2012 and commit to mobilise \$100 billion annually by 2020 .

- Possibility to review the global temperature rise target limit of $2^{\circ} \mathrm{C}$ to a value of $1.5^{\circ} \mathrm{C}$ in 2015 following the conclusions of the next IPCC assessment report. 